\title{
Evaluation of Unconventional Water Resources Based on Knowledge Granularity
}

\author{
Xin $\mathrm{WU}^{1}$, Qingbo $\mathrm{Wen}^{1}$, Liming $\mathrm{HU}^{1^{*}}$, and Mingyang Liu ${ }^{1}$ \\ ${ }^{1}$ State Key Laboratory of Hydro-Science and Engineering, Department of Hydraulic Engineering, \\ Tsinghua University, Beijing, 100084, CHINA
}

\begin{abstract}
Water resources are important natural resources and play a key role in economic development and social life. China is one of the countries with the most serious water shortage in the world. In the next few decades, the contradiction between supply and demand of water resources will always plague China. Increasing the use of unconventional water resources to mitigate the water crisis is necessary way to achieve a sustainable development. There has been no effective standard yet in China to evaluate the exploitation level and potential of unconventional water resources. This study describes the current status of the exploitation and aims at establishing an evaluation system incorporating the three relevant factors, namely, driving, restrictive, and risk factors respectively, and provides a theoretical basis for the management of unconventional water resources in China. In order to mine the relationship between data and evaluation indexes, the rough set theory is adopted to determine the weight and objectively reflect the importance of each evaluation index. On the basis of the evaluation system, relevant data from 2006 to 2017 in Beijing were selected, and the results show that the urgency of unconventional water resources development in Beijing was generally on the rise with a small fluctuation range.
\end{abstract}

Keywords: unconventional water resources (UWR); rough set; knowledge granularity

\section{Introduction}

Water resources play a key role in people's daily life and social development. In recent years, water shortage is becoming a serious problem in China with the rapid development of Chinese economy. From the western countries' experience in coping with the water resources crisis[1], the development and utilization of unconventional water resources is an important way to make up the shortage of water resources in China. Unconventional water resources mainly include rainwater resources, reclaimed water resources, seawater, brackish water and other water resources, which are different from surface water and groundwater in general

* Corresponding author: gehu@tsinghua.edu.cn (L. Hu). 
sense [2-4]. As the contradiction between limit supply and vast demand of water resources intensifies, the Chinese Ministry of Water Resources issued the guidance on integrating unconventional water sources into the unified allocation of water resources in 2017, trying to further improve the utilization efficiency of regional water resources by improving the development and utilization of unconventional water resources, including reclaimed water, rainwater, brackish water and desalinated seawater. It is particularly important to evaluate the present situation and development trend of unconventional water sources scientifically.

At present, there are many studies on evaluation methods of unconventional water resources utilization, but no unified standard and recognized method has been formed so far. Scholars usually use analytic hierarchy process (AHP) or principal component analysis (PCA) to establish and conduct analysis. For example, Bojan (2008) used Fuzzy AHP method to evaluate water resources in some areas of the the Paraguacu River Basin, Brazil [5]; Jung et al (2016) used PCA method in the evaluation of water situation in the Naidong river basin [6]. The similarity between these two methods is establishing the evaluation index system first, then determining the weight level according to the expert's rating of the importance of each index, and finally bringing the weight into the evaluation. Another method to evaluate water resources utilization is using rough set theory. As early as in 2002, Pawlak proposed the concept of knowledge granularity deduced it theoretically [7]. In terms of basin water resources allocation and evaluation of future water resources, many scholars put forward a new theoretical framework based on the rough set theory. For example, Zeng et al. (2006) provided a new idea for water resources allocation in arid areas based on the conflict analysis method of rough set [8], which avoids too much reliance on the experts' experience comparing with AHP and PCA [9]. The greater the amount of information, the more objective the attribute weight was.

This study aims to establish an evaluation system on rough set by determining weight based on the data from 31 provinces and cities in China, and then evaluates the usage of unconventional water resource in city of Beijing.

\section{Methods}

This paper adopts the method based on the knowledge granularity of rough set to establish an evaluation system. There are three main steps. The first step is to select appropriate evaluation index from the actual data, then divide the selected evaluation indicators according to the actual situation reasonably, and finally calculate the importance of the index and determine the weight.

\subsection{Building Evaluation Index System}

Utilization of unconventional water resources is a multi-objective issue which is coherent with natural, social, economic factors, and so on. This study attributes the water resources utilization usage to driving factors, restrictive factors and risk factor [3]. These three subsystems depend on influence and restrict among them. In order to fully consider the driving factors of unconventional water resources utilization from both the supply and demand sides. On the supply side is investigated. The guarantee rate of conventional water supply is low due to the limitation of endowment conditions of the regional water resource, while the volume of the unconventional water resources can be large and stable. From the perspective of the demand side, the increased water resource gap can provide stable customers for unconventional water resources, and relevant policies and regulations also guarantee the usage of unconventional water resources. 
The constraints for unconventional water resources development and utilization include many complicated factors, such as natural, social and economic factors on the influence degree of exploitation and utilization of reclaimed water in different through literature survey and field survey.

The constraint for unconventional water resources development and utilization are mainly divided into engineering conditions, economic conditions, technological level, policies, regulation constraints of ecological environment, as well as social acceptance constraints. The constraints of engineering conditions involve the quantity and quality of water resources, the completeness of supporting pipe network, corrosion resistance of the water supply facilities, etc. Economic constraints involve local economic development level, project investment, water production cost, etc. Technical level constraints include treatment technology and utilization of technical measures. Risk factor involves human health, ecological environment, facilities and equipment, the three links of production, transmission, and distribution, as well as the use of reclaimed water. After trawling through the relevant literature and combining the current situation of water resource utilization of China in recent years, the indicators are preliminarily selected in each subsystem, and the results are shown in Table 1. [10-16]

Table 1. Three rule layers and the criteria, index, and units.

\begin{tabular}{|c|c|c|c|}
\hline Rule Layer & Criteria & Index & Unit \\
\hline \multirow[b]{2}{*}{$\begin{array}{l}\text { Driving } \\
\text { factors }\end{array}$} & Water endowment & $\begin{array}{c}\text { Water resources per capita } \mathrm{C} 1 \\
\text { Water production coefficient } \mathrm{C} 2 \\
\text { Runoff modulus C3 } \\
\text { Rainfall C4 }\end{array}$ & $\begin{array}{l}\mathrm{m}^{3} / \text { person } \\
\% \\
10 \mathrm{~m}^{3} / \mathrm{km}^{2} \\
\mathrm{~mm}\end{array}$ \\
\hline & $\begin{array}{l}\text { Utilization of } \\
\text { conventional water } \\
\text { resources }\end{array}$ & $\begin{array}{l}\text { Utilization rate of surface water C5 } \\
\text { Groundwater recovery rate C6 } \\
\text { Urban per capita domestic water C7 } \\
\text { Rural per capita living water C8 } \\
\text { GDP per water consumption C9 } \\
\end{array}$ & $\begin{array}{c}\% \\
\% \\
\mathrm{~L} \\
\mathrm{~L} \\
\mathrm{~m}^{3} / 10^{4} \text { Yuan } \\
\end{array}$ \\
\hline \multirow{5}{*}{$\begin{array}{l}\text { Restrictive } \\
\text { factors }\end{array}$} & $\begin{array}{c}\text { Engineering } \\
\text { conditions }\end{array}$ & $\begin{array}{c}\text { The ratio of unconventional water supply pipeline } \\
\text { to municipal pipeline } \mathrm{C} 10\end{array}$ & $\%$ \\
\hline & $\begin{array}{l}\text { Economic } \\
\text { conditions }\end{array}$ & $\begin{array}{c}\text { Urbanization level C11 } \\
\text { Average GDP C12 } \\
\text { New investment in factories accounted for the share } \\
\text { of public investment C13 } \\
\text { The cost of unconventional water treatment C14 }\end{array}$ & $\begin{array}{c}\% \\
\text { Yuan } \\
\% \\
\text { Yuan/t }\end{array}$ \\
\hline & $\begin{array}{l}\text { Technological } \\
\text { level } \\
\text { Policies and } \\
\text { regulations } \\
\end{array}$ & $\begin{array}{c}\text { Treatment process and utilization measures C15 } \\
\text { Regulations and policy standards C16 }\end{array}$ & $\begin{array}{l}\text { qualitative analysis } \\
\text { qualitative analysis }\end{array}$ \\
\hline & $\begin{array}{l}\text { Constraints of } \\
\text { ecological } \\
\text { environment }\end{array}$ & $\begin{array}{c}\text { Forest coverage rate } \mathrm{C} 17 \\
\text { The proportion of ecological environment water in } \\
\text { total water consumption } \mathrm{C} 18 \\
\text { Soil and water conservation } \mathrm{C} 19\end{array}$ & $\begin{array}{c}\% \\
\% \\
\text { qualitative analysis }\end{array}$ \\
\hline & $\begin{array}{l}\text { Social acceptance } \\
\text { constraints }\end{array}$ & Average age of education $\mathrm{C} 20$ & year \\
\hline $\begin{array}{l}\text { Risk } \\
\text { factor }\end{array}$ & $\begin{array}{l}\text { Human health, } \\
\text { ecological } \\
\text { environment }\end{array}$ & Human and environmental impacts $\mathrm{C} 21$ & qualitative analysis \\
\hline
\end{tabular}

\subsection{Partition of Index Ideal Set}

Before evaluating the development potential of regional unconventional water resources, it is necessary to reasonably divide the selected evaluation indicators according to the actual situation of China and the characteristics of various regions. Therefore, we first investigate the selection of evaluation index in the general scope of the home and abroad, on the basis of its unconventional water resources development has a positive impact. The target ideal set is 
ranked by the levels from $\mathrm{I}$ to $\mathrm{V}$, which represent the impact on unconventional water resources development from negative to positive. If the score reaches 5 in some areas, it means urgent need of developing unconventional with huge potential for development and utilization of water resources.

The standards of the unconventional water resources are shown in Table 2. [10-16]

Table 2. Ideal set of index.

\begin{tabular}{|c|c|c|c|c|c|}
\hline Index & I & II & III & IV & $\mathbf{V}$ \\
\hline $\mathrm{C} 1$ & $>2000$ & $1500-2000$ & $1000-1500$ & $500-1000$ & $<500$ \\
\hline $\mathrm{C} 2$ & $>65$ & $40-65$ & $20-40$ & $10-20$ & $<10$ \\
\hline $\mathrm{C} 3$ & $>45$ & $20-45$ & $10--20$ & $5-10$ & $<5$ \\
\hline $\mathrm{C} 4$ & $>1600$ & $1000-1600$ & $600-1000$ & $200-600$ & $<200$ \\
\hline $\mathrm{C} 5$ & $<30$ & $30-50$ & $50-70$ & $70-90$ & $>90$ \\
\hline $\mathrm{C} 6$ & $<30$ & $30-50$ & $50-70$ & $70-90$ & $>90$ \\
\hline $\mathrm{C} 7$ & $>230$ & $180-230$ & $130-180$ & $100-130$ & $<100$ \\
\hline $\mathrm{C} 8$ & $>85$ & $75-85$ & $65-75$ & $50-65$ & $<50$ \\
\hline C9 & $<50$ & $50-150$ & $150-250$ & $250-350$ & $>350$ \\
\hline $\mathrm{C} 10$ & $<2$ & $2-3$ & $3-4$ & $4-5$ & $>5$ \\
\hline $\mathrm{C} 11$ & $<55$ & $55-65$ & $65-75$ & $75-85$ & $>85$ \\
\hline $\mathrm{C} 12$ & $<5000$ & $5000-10000$ & $10000-30000$ & $30000-50000$ & $>50000$ \\
\hline $\mathrm{C} 13$ & $<4$ & $4-6$ & $6-8$ & $8-10$ & $>10$ \\
\hline $\mathrm{C} 14$ & $>6$ & $5-6$ & $4-5$ & $3-4$ & $<3$ \\
\hline $\mathrm{C} 15$ & & & qualitative analysis & & \\
\hline $\mathrm{C} 16$ & & & qualitative analysis & & \\
\hline $\mathrm{C} 17$ & $<10$ & $10-30$ & $30-50$ & $50-60$ & $>60$ \\
\hline $\mathrm{C} 18$ & $<5$ & $5-10$ & $10-15$ & $15-30$ & $>30$ \\
\hline $\mathrm{C} 19$ & & & qualitative analysis & & \\
\hline $\mathrm{C} 20$ & $<8$ & $8-9$ & $9-10$ & $10-12$ & $>12$ \\
\hline $\mathrm{C} 21$ & & & qualitative analysis & & \\
\hline
\end{tabular}

\subsection{Rough set}

Rough set theory was put forward by the Polish scholar Pawlak, and then got great development in data processing and artificial intelligence. By adopting rough set theory, the problem of uncertainty can be handled objectively only by internal relation between data. In the field of water resources evaluation, the relationship between data and evaluation indexes can be mined through rough set theory, which can objectively show the importance of each evaluation index, so as to avoid the problem of relying too much on expert experience [1719].

For a set of information system, based on rough set theory, we can partition it by the attributes set $X$ or a Single evaluation attribute $x$. The importance of evaluation attribute $x$ itself and the overall attributes can be calculated using $\operatorname{Sig}_{x}(X)$ and $\operatorname{Sig}(x)$. The evaluations of attribute weights can be calculated respectively with the importance of evaluation theory. The method can be effectively implemented by data mining through the inner link of the specific way of calculation, shown as follows:[9]

$$
\operatorname{Sig}_{x}(X)=1-\frac{|X Y(x)|}{X}
$$




$$
\begin{gathered}
\operatorname{Sig}(x)=1-\frac{|\{x\}|}{(\operatorname{Card}(U))^{2}} \\
\operatorname{SIG}(x)=\operatorname{Sig}_{x}(X)+\operatorname{Sig}(x)
\end{gathered}
$$

Among which, $U / X=\left\{X_{1}, X_{2} \cdots, X_{n}\right\},|X|=\sum_{i=1}^{n}\left(\operatorname{Card}\left(X_{i}\right)\right)^{2} . \operatorname{SIG}(x)$ reflects the ultimate attribute importance of the index.

\section{Analysis and Evaluation}

This paper analyzes the internal relationship of indicator data to obtain the importance of each indicator, and normalizes the weight of each indicator. It takes Beijing city as a case to verify the effectiveness and feasibility of this method, which provides a theoretical basis for determining the weight of non-conventional water resources evaluation index more objectively, rationally and accurately.

\subsection{Data}

In this study, the year 2015 was taken as the base year, and the 31 major provinces and cities were selected as the research objects to obtain the index weights in line with the development of unconventional water resources in China. The evaluation index data are from the National Bureau of Statistics Data. The specific data is shown in Table 3.

\begin{tabular}{|c|c|c|c|c|c|c|c|c|c|c|c|c|c|c|c|c|c|}
\hline & 1 & & 3 & 4 & & & C & $\mathrm{C} 8$ & 9 & $\mathrm{C} 10$ & $\mathrm{C} 11$ & $\mathrm{C} 12$ & C13 & C14 & $\mathrm{C} 17$ & C18 & 20 \\
\hline $\mathrm{U}$ & & & & & & & & & & & & & 1 & 3 & 42 & & \\
\hline $\mathrm{U} 2$ & & & & & & & & & & & & & 2 & & & 7 & 50 \\
\hline U3 & & & & & & & & & & 3.4 & & & 5 & & & 2.6 & .87 \\
\hline $\mathrm{U}$ & & & & & & & & & & 3.5 & & & 8 & & & 4.8 & 30 \\
\hline $\mathrm{U}$ & & & & & & & & & & 7.2 & & & 3 & & 21 & 7.9 & .00 \\
\hline U & & 17 & & & & 70 & & & & 1.2 & & & $y$ & + & 38 & 3.5 & .91 \\
\hline $\mathrm{U}^{\prime}$ & & 20 & 17.61 & & 32 & 35 & & & & 4 & & & 1 & 7 & 40 & 7 & 3I \\
\hline U\& & & 33 & 17.94 & & 29 & 59 & & & & 0.4 & & & 4 & 2 & 3 & .4 & (ד \\
\hline $\mathrm{U}$ & & 6 & 100. & & 19 & 1 & & & & 0 & & & 3 & 6 & 11 & 0.8 & 02 \\
\hline U10 & & 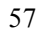 & & 10 & 12 & 7 & & & & 0.6 & & & 0 & & 16 & 0.5 & \\
\hline U11 & & 78 & & & 14 & 1 & & & & 0.1 & & & 8 & & 61 & 2.7 & 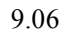 \\
\hline$+2>$ & & 56 & 6 & & 28 & 16 & & & & 0.2 & & & 3 & & 29 & 1.7 & \\
\hline $\mathrm{U}$ & & 63 & 108.7 & & 15 & 2 & & & & 0.4 & & & 4 & & 66 & 1.6 & \\
\hline U14 & 3 & 71 & 119. & & 13 & 2 & & & & 0.8 & & & 3 & 8 & 63 & 0.8 & \\
\hline 1 & & 15 & 1 & 696 & 144 & 65 & 1 & & $34+2$ & 2.4 & 0 & & 4 & .89 & 17 & 2.7 & 0 \\
\hline U16 & 4 & 24 & 2 & 746 & 47 & 69 & 111. & & $56-3>$ & 1.3 & 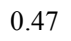 & 3 & 9 & 3.48 & 24 & 2.7 & f.00 \\
\hline U17 & 1738.05 & 49 & 54.63 & 5 & 28 & 3 & 205. & & & 0 & 0 & 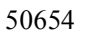 & 6 & 4.33 & 38 & .2 & 9.11 \\
\hline U18 & 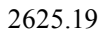 & . & & 136786 & 16 & 4 & 20 & 79.28 & 115.01 & 0 . & 1 & 42754 & 7 & 4.65 & 8 & 0.8 & .02 \\
\hline
\end{tabular}

Table 3. The actual data of $\mathbf{3 1}$ major provinces and cities. 


\begin{tabular}{|c|c|c|c|c|c|c|c|c|c|c|c|c|c|c|c|}
\hline 19 & 343.02 & 60 & 107. & 6.38 & 22 & 3 & 248.9590 .5260 .77 & 0 & 0.09 & 67503 & 9 & 4.65 & 59 & 2 & 8 \\
\hline $\mathrm{J} 20$ & 4021.99 & 68 & 102.62 & 1315.79 & 12 & 2 & 255.6582 .65183 .06 & 0 & 0.47 & 35190 & 2 & 6.24 & 57 & 0.8 & 8.75 \\
\hline 21 & 4090.04 & 27 & 56.44 & 62.11 & 21 & 6 & 263.7879 .28121 .53 & 3.3 & 5 & 40818 & 2 & 3.46 & 5 & 4 & 10 \\
\hline $\mathrm{U} 22$ & 1835.38 & 51 & 55.30 & 1146.64 & 17 & 1 & 151.9776 .3251 .22 & 0.6 & 0.61 & 52321 & 2 & 45 & 45 & 1 & 96 \\
\hline U23 & 2970.88 & 49 & 45.77 & 926.60 & 10 & 3 & 204.1365 .8178 .83 & 0 & & 5775 & 4 & 04 & 35 & .8 & 35 \\
\hline $\mathrm{U} 24$ & 2678.92 & 62 & 65.49 & 1125.96 & 8 & 1 & 163.7872 .1290 .74 & 0.2 & 0.42 & 9847 & 7 & 26 & 37 & .7 & 09 \\
\hline $\mathrm{U} 25$ & 4139.72 & 44 & 47.50 & 1002.95 & 8 & 1 & 132.7785 .04109 .70 & 1.6 & 0.43 & 28806 & 3 & 5.24 & 50 & .3 & .79 \\
\hline $\mathrm{U} 26$ & 149370.12 & 55 & 31.45 & 594.52 & 1 & 0 & .10297 .16 & 0 & 0.28 & 31999 & 0 & 7.06 & 12 & 0.2 & .22 \\
\hline 7 & 1078.65 & 23 & 16.20 & 735.14 & 18 & 28 & 155.7165 .2449 .83 & 2.2 & 0.54 & 47626 & 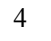 & 6.10 & 41 & 2.8 & 9.14 \\
\hline $\mathrm{U} 28$ & 934.61 & 17 & 4.47 & 394.29 & 47 & 28 & 132.0049 .51182 .12 & 1.9 & 0.43 & 25517 & 0 & 4.12 & 11 & 1.5 & 8.32 \\
\hline 29 & 12786.95 & 24 & 8.17 & 343.18 & 4 & 1 & 168.7662 .99108 .81 & 2.3 & 0.50 & 41252 & 25 & 5.05 & 0 & 1.5 & 8.04 \\
\hline 30 & 157.48 & 6 & 1.47 & 278.70 & 911 & 26 & 171.6759 .60240 .181 & 122.7 & 0.55 & 44035 & 3 & 3.94 & 12 & 3.3 & 8.55 \\
\hline & 4454.61 & 33 & 5.59 & 175.46 & 51 & 24 & 170.5562 .57623 .93 & 3.2 & 0.4 & 40036 & 4 & 3.59 & 4 & 0.9 & 9.18 \\
\hline
\end{tabular}

Note:

\begin{tabular}{cccccccc}
\hline Code & Name & Code & Name & Code & Name & Code & Name \\
\hline U1 & Beijing & U9 & Shanghai & U17 & Hubei & U25 & Yunnan \\
U2 & Tianjin & U10 & Jiangsu & U18 & Hunan & U26 & Tibet \\
U3 & Hebei & U11 & Zhejiang & U19 & Guangdong & U27 & Shaanxi \\
U4 & Shanxi & U12 & Anhui & U20 & Guangxi & U28 & Gansu \\
U5 & Inner Mongolia & U13 & Fujian & U21 & Hainan & U29 & Qinghai \\
U6 & Liaoning & U14 & Jiangxi & U22 & Chongqing & U30 & Ningxia \\
U7 & Jilin & U15 & Shandong & U23 & Sichuan & U31 & Xinjiang \\
\hline U8 & Heilongjiang & U16 & Henan & U24 & Guizhou & &
\end{tabular}

\subsection{Determination of the Index Weight}

Based on the calculation methods above, we can calculate $\operatorname{Sig}_{x}(\mathbf{X}), \operatorname{Sig}(\mathbf{x})$, and $\operatorname{SIG}(\mathbf{x})$. After normalizing SIG(x), the weights are obtained and the results are shown in Table 4. After trawling through the relevant literature and combining the current situation of water resource utilization of China in recent years, the weights of the three Rule Layer are 0.4,0.4,0.2.

Table 4. The calculating results of rough sets $(\operatorname{Sigx}(X), \operatorname{Sig}(x), \operatorname{SIG}(x))$, and weight.

\begin{tabular}{ccccccc}
\hline Rule Layer & Index & Sig $_{\mathbf{x}}(\mathbf{X})$ & $\operatorname{Sig}(\mathbf{x})$ & $\mathbf{S I G ( \mathbf { x } )}$ & Weight & $\begin{array}{c}\text { Overall } \\
\text { Weight }\end{array}$ \\
\hline \multirow{5}{*}{ Driving } & C1 & 0.75 & 0.06 & 0.81 & 0.13 & 0.051 \\
factors & C2 & 0.74 & 0.00 & 0.74 & 0.12 & 0.047 \\
& C3 & 0.68 & 0.00 & 0.68 & 0.11 & 0.043 \\
& C5 & 0.72 & 0.06 & 0.78 & 0.12 & 0.049 \\
& C6 & 0.59 & 0.00 & 0.59 & 0.09 & 0.037 \\
& C7 & 0.51 & 0.00 & 0.51 & 0.08 & 0.032 \\
& C8 & 0.71 & 0.06 & 0.77 & 0.12 & 0.048 \\
& C9 & 0.77 & 0.06 & 0.83 & 0.13 & 0.053 \\
\hline
\end{tabular}




\begin{tabular}{ccccccc}
\hline & $\mathrm{C} 10$ & 0.54 & 0.00 & 0.54 & 0.08 & 0.032 \\
& $\mathrm{C} 11$ & 0.67 & 0.00 & 0.67 & 0.10 & 0.039 \\
& $\mathrm{C} 12$ & 0.58 & 0.00 & 0.58 & 0.08 & 0.034 \\
Restrictive & $\mathrm{C} 13$ & 0.70 & 0.00 & 0.70 & 0.10 & 0.041 \\
factors & $\mathrm{C} 14$ & 0.76 & 0.00 & 0.76 & 0.11 & 0.044 \\
& $\mathrm{C} 15$ & 0.66 & 0.00 & 0.66 & 0.10 & 0.039 \\
& $\mathrm{C} 16$ & 0.64 & 0.00 & 0.64 & 0.09 & 0.037 \\
& $\mathrm{C} 17$ & 0.72 & 0.06 & 0.78 & 0.11 & 0.045 \\
& $\mathrm{C} 18$ & 0.18 & 0.00 & 0.18 & 0.03 & 0.010 \\
& $\mathrm{C} 19$ & 0.72 & 0.00 & 0.72 & 0.10 & 0.042 \\
Risk factor & $\mathrm{C} 20$ & 0.63 & 0.00 & 0.63 & 0.09 & 0.037 \\
\hline
\end{tabular}

\subsection{Evaluation result}

On the basis of overall weight, we selected the related data of Beijing from 2006 to 2017 in Table 5. The overall weight of the index layer obtained above (Table 4) is multiplied by the rating of each index to obtain the final evaluation result in Table 6. According to the evaluation results, the urgency of unconventional water resources development in the Beijing show an overall upward trend, with a small range of fluctuations. The reasons can be elaborated as follows: The utilization of water resources in Beijing still aims at economic orientation at present, and due to the further aggravation of water shortage, the demand for the development and utilization of unconventional water resources is increasing. The urgency of unconventional water development was eased in 2012 and 2016 when rainfall was abundant and the increase in conventional water resources made up for the shortfall in water demand. It is also in line with the current national incentive to use unconventional water resources.

Table 5. The actual data about utilization of UWR in Beijing from 2006 to 2017.

\begin{tabular}{ccccccccccccc}
\hline & 2006 & 2007 & 2008 & 2009 & 2010 & 2011 & 2012 & 2013 & 2014 & 2015 & 2016 & 2017 \\
\hline C1 & 22.10 & 23.81 & 34.20 & 21.80 & 23.10 & 26.81 & 39.50 & 24.80 & 20.30 & 26.80 & 35.10 & 29.80 \\
C2 & 23 & 25 & 36 & 23 & 25 & 28 & 42 & 26 & 22 & 28 & 37 & 32 \\
C3 & 13.39 & 14.42 & 20.71 & 13.20 & 13.99 & 16.24 & 23.93 & 15.02 & 12.30 & 16.23 & 21.26 & 18.05 \\
C4 & 318.00 & 483.90 & 626.30 & 480.60 & 522.50 & 720.60 & 733.20 & 578.90 & 461.50 & 458.60 & 669.10 & 592.00 \\
C5 & 96 & 75 & 46 & 106 & 100 & 78 & 44 & 88 & 143 & 113 & 81 & 103 \\
C6 & 63 & 67 & 93 & 69 & 75 & 83 & 106 & 77 & 70 & 96 & 138 & 123 \\
C7 & 120.70 & 107.00 & 99.65 & 75.21 & 83.35 & 85.06 & 89.50 & 89.10 & 92.58 & 85.79 & 92.54 & 92.00 \\
C8 & 154.70 & 166.80 & 187.22 & 192.10 & 174.92 & 172.62 & 171.79 & 196.85 & 187.52 & 183.81 & 173.10 & 188.00 \\
C9 & 41.26 & 34.56 & 30.81 & 28.59 & 24.94 & 21.66 & 20.08 & 18.38 & 17.58 & 16.60 & 15.12 & 14.11 \\
C10 & 2 & 2 & 3 & 3 & 3 & 4 & 5 & 4 & 5 & 5 & 6 & 6 \\
C11 & 84 & 85 & 85 & 85 & 86 & 86 & 86 & 86 & 86 & 87 & 87 & 87 \\
C12 & 52964 & 61470 & 66098 & 68406 & 73856 & 81658 & 87475 & 94648 & 99995 & 106497 & 118198 & 128927 \\
C13 & 1 & 1 & 1 & 1 & 1 & 1 & 1 & 1 & 1 & 1 & 1 & 1 \\
C14 & 4.30 & 4.30 & 4.20 & 4.20 & 4.10 & 4.10 & 4.10 & 3.90 & 3.90 & 3.83 & 3.80 & 3.80 \\
C17 & 35.90 & 36.50 & 36.50 & 36.70 & 37.00 & 37.60 & 38.60 & 40.10 & 41.00 & 41.60 & 35.84 & 35.84 \\
\hline
\end{tabular}




\begin{tabular}{rccrrrrrrrrrr}
\hline $\mathrm{C} 18$ & 9 & 9 & 9 & 10 & 11 & 13 & 16 & 16 & 18 & 19 & 19 & 32 \\
$\mathrm{C} 20$ & 11.00 & 11.00 & 11.00 & 11.00 & 11.00 & 11.55 & 11.00 & 11.00 & 11.00 & 11.85 & 11.00 & 11.00 \\
\hline
\end{tabular}

Table 6. Evaluation level in Beijing from 2006 to 2017.

\begin{tabular}{ccccccc}
\hline Year & 2006 & 2007 & 2008 & 2009 & 2010 & 2011 \\
\hline Evaluation level & 3.41 & 3.41 & 3.35 & 3.50 & 3.61 & 3.60 \\
\hline Year & 2012 & 2013 & 2014 & 2015 & 2016 & 2017 \\
\hline Evaluation level & 3.51 & 3.70 & 3.77 & 3.91 & 3.78 & 3.92 \\
\hline
\end{tabular}

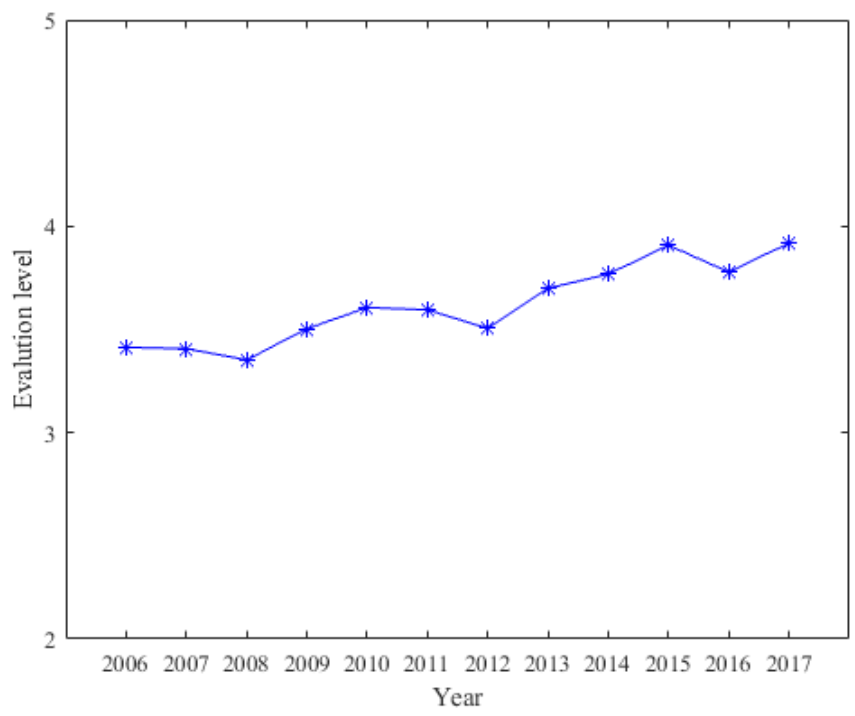

Fig. 1. Evaluation level of Beijing from 2006 to 2017.

\section{Conclusions}

Unconventional water resources utilization is an important way to make up for the shortage of water resources in China. At present, there are many researches on the evaluation methods of unconventional water resources utilization, but no unified standard and recognized methods have been formed. In the evaluation of unconventional water resources, the determination of index weight is the key to influence the evaluation result. Whether the weighting method is reasonable and whether the weighting result is objective directly affects the accuracy and validity of the evaluation result.

The evaluation of unconventional water resources was studied based on the rough set theory, to determine the rule layer internal index weight, which can objectively reflect the study area the intrinsic relationships between each evaluation index. Moreover, by means of the incorporation of expert experience on the basis of the actual development situation to determine the overall weight rule layer, the evaluation system can accurately reflect the objective conditions and effectiveness.

The 31 provinces were used as the object of evaluation, then the data processed by the weighted method based on the knowledge granularity of rough set, and the attribute importance of rough set knowledge granularity for unconventional water resources 
evaluation index system is derived from the objective original data of real sample land, from which the correlation and importance of each index are excavated. On the basis of overall weight, relevant data from 2006 to 2017 in Beijing were selected, and the results show that the urgency of unconventional water resources development in Beijing was generally on the rise with a small fluctuation range. The evaluation results are in good agreement with the actual situation.

This research is funded by National Key R\&D Program of China (Project No. 2017YFC0403501).

\section{References}

[1] J.O. Jaber, M.S. Mohsen, Desalination, 136(1-3): 83-92(2001)

[2] B.K. Karimov, M. Matthies, B.G. Kamilov, The Global Water System in the Anthropocene. Springer International Publishing (2014).

[3] T. Li, W.Y. Dong, Z.J. Dong, Water Resources and Hydropower Engineering, 43(8), 7881. (2012)

[4] W.Z. Liu, S. Liu, Groundwater (2008).

[5] B. Srdjevic, Y.D.P. Medeiros. Water Resour. Manag, 22.7:877-894(2008)

[6] K.Y. Jung, K.L. Lee, et al. Environmental Technology \& Innovation, S2352186415300067(2015)

[7] Z. Pawlak, IEEE World Congress on Computational Intelligence (Cat. No.98CH36228) $\operatorname{IEEE}(2002)$.

[8] Z.T. Gong, et al. International Conference on Machine Learning \& Cybernetics IEEE, (2009)

[9] B.H. Men, et al. Water, 9.11:852-.(2017)

[10] D. Wu, Journal of Natural Resources (2014).

[11] W.Q. Gu, D.G. Shao, Y.F. Jiang, Water Resour. Manag, 26.12:3479-3493(2012)

[12] R. Wang, X.W. Chen, et al. Science of Soil \& Water Conservation, 12.5:77-83(2014)

[13] Z.Y. Zhong, L.Y. Chai, et al. China Environmental Science, 30:41-45(2010)

[14] C.Z. Sun, H.X. Li, Journal of Water Resources and Water Engineering,22.4:633639.(2007)

[15] Y.H. Zhou, J.W. Huang, International Conference on IEEE(2007)

[16] A. Hamdy, Acta Horticulturae,573:159-174(2002)

[17] Z. Pawlak, Inf. Sci, 147.1:1-12(2002)

[18] Z. Pawlak, A. Skowron, Inf. Sci, 177.1:28-40(2007)

[19] Y. Icaga, Ecol. Indic, 7.3:0-718(2007) 